\title{
O EMBATE NA CONSTRUÇÃO IDENTITÁRIA DO PERSONAGEM ERIC EFFIONG NA SÉRIE SEX EDUCATION
}

\author{
Leila Heloise da Silva Jerônimo ${ }^{1}$ \\ Marília Varella Bezerra de Faria ${ }^{2}$
}

\begin{abstract}
RESUMO: A série britânica Sex Education alavancou a discussão sobre sexualidade, principalmente no que diz respeito às questões que envolvem a homossexualidade e os desafios da comunidade LGBTQIA+ ao enfrentar um mundo majoritariamente heteronormativo. Em meio às forças que agem sobre os personagens da série, levando-os e trazendo-os ao centro, deparamo-nos com as que agem sobre Eric Effiong, adolescente negro, afeminado, filho de pais protestantes, que passa por mudanças significativas em seu comportamento após um trauma resultante do preconceito por parte da sociedade. Pensando nisso, objetivamos, neste artigo, discutir a construção identitária de Eric Effiong, a partir da visão do personagem sobre si, assim como da visão daqueles que estão no seu entorno. Para isso, situamos o nosso trabalho no âmbito da Linguística Aplicada, ancorados nos postulados do Círculo de Bakhtin (2011, 2015), de Butler (2003), de Louro (2000) e de Hall (2006), para que possamos discutir as forças centrífugas e centrípetas, o corpo, a sexualidade e a identidade. A partir de um estudo qualitativo de cunho interpretativista, utilizaremos como corpus de análise enunciados do personagem em questão e daqueles que interagem com ele em momentos específicos. Os resultados preliminares apontam para uma multiplicidade de identidades do personagem Eric Effiong.
\end{abstract}

PALAVRAS-CHAVE: Linguagem. Construção identitária. Gênero social. Sexualidade. Sex Education.

\begin{abstract}
The British TV series Sex Education has raised discussions on sexuality, especially on issues concerning homosexuality and the challenges faced by LGBTQ+ community, all immersed in a predominantly heteronormative world. Different forces move the characters of this series back and forth and Eric Effiong, a black homosexual teenager whose parents are protestant, goes through significant behavioral changes due to a trauma caused by prejudice. In this article, we aim to present Eric Effiong's identity construction, built upon his viewpoint about himself as well as upon other characters' viewpoints. Our research is situated within the area of Applied Linguistics and based on the theoretical principles of the Bakhtin Circle (2011, 2015), Butler (2003), Louro (2000), and Hall (2006), with the purpose of discussing the concepts of centrifugal and centripetal forces, body, sexuality and identity. This interpretive qualitative study examines both Eric Effiong's utterances and other characters' utterances. The preliminary findings lead to multifold identities for Eric Effiong.
\end{abstract}

KEYWORDS: Language. Identity. Gender. Sexuality. Sex Education.

\section{Introdução}

\footnotetext{
${ }^{1}$ Mestranda em Estudos da Linguagem pela Universidade Federal do Rio Grande do Norte (UFRN) - Natal Rio Grande do Norte - Brasil. E-mail: leila.heloise@gmail.com.

${ }^{2}$ Professora Doutora da Universidade Federal do Rio Grande do Norte (UFRN) - Natal - Rio Grande do Norte - Brasil. E-mail: mariliavbf@yahoo.com.br.
} 
A discussão sobre gênero social, sexo e sexualidade, junto ao processo de autoconhecimento dos corpos dos sujeitos, tem ganhado força nos últimos anos, principalmente pelo apoio que vem recebendo dos vários meios de comunicação que dão ênfase ao assunto. Desde a década de sessenta, “o debate sobre as identidades e as práticas sexuais e de gênero vem se tornando cada vez mais acalorado, especialmente provocado pelo movimento feminista, pelos movimentos de gays e de lésbicas e sustentado [...] por todos aqueles e aquelas que se sentem ameaçados" (LOURO, 2000, p. 7) pelos julgamentos em torno dos seus corpos e de suas escolhas.

Ao longo dos anos, a comunidade LGBTQIA $+{ }^{3}$ passou a ter a sua causa revozeada de forma mais efetiva nas telas de cinema, nas telenovelas contemporâneas da TV aberta e em filmes, séries e minisséries produzidas pelas plataformas de streaming ${ }^{4}$, que também passaram a trazer à tona essa discussão em suas produções artísticas, a saber: Filadélfia (1993); Meninos não choram (1999); Café da manhã em Plutão (2005); Milk: a voz da igualdade (2008); Orange is new the black (2013); Hoje eu quero voltar sozinho (2014); Com amor, Simon (2018); RuPaul's drag race etc. A adesão à causa do movimento LGBTQIA+, com ênfase nas dificuldades desse grupo em lidar com uma sociedade majoritariamente heteronormativa que age, mesmo que indiretamente, sobre o modo como eles devem se portar no mundo, vem permitindo que, aos poucos, a visão estigmatizada em torno da sexualidade e do gênero possa ser desmistificada.

A sexualidade e o gênero estão diretamente ligados às identidades dos sujeitos e são, assim como estas, construídos socialmente, ou seja, os corpos ganham sentido nas e pelas relações sociais (LOURO, 2000). É por esse motivo que quando são pautas de grandes produções artísticas, as questões sobre sexualidade e gênero social são bastante discutidas para que possam ser disseminadas de modo a alcançar um número cada vez maior de pessoas adeptas e abertas a compreender a importância delas. Com o olhar voltado para essa construção social em torno da identidade e da sexualidade dos indivíduos, empresas como a Netflix ${ }^{5}$, por exemplo, estão tentando construir conteúdos voltados para a temática, os quais

\footnotetext{
3 A sigla LGBTQIA+ representa a diversidade, a saber: lésbicas, gays, bissexuais, transsexuais, travestis, transgêneros, queers, interssexuais, assexuais, demissexuais, panssexuais e intrassexuais.

${ }^{4}$ Os serviços de streaming possibilitam a transmissão de conteúdos pela internet, em tempo real, sem que haja a necessidade do usuário efetuar downloads para ter acesso a filmes, a séries, a músicas, a livros etc.

5 “A Netflix é o principal serviço de streaming de entretenimento do mundo, com mais de 167 milhões de assinaturas pagas em mais de 190 países, com séries de TV, documentários e longas-metragens em uma ampla variedade de gêneros e idiomas. Os membros podem assistir o quanto quiserem, a qualquer hora, em qualquer lugar, em qualquer tela conectada à Internet. Os membros podem reproduzir, pausar e retomar a exibição, tudo sem comerciais ou compromissos”. Disponível em: https://media.netflix.com/en/about-netflix. Acesso em: 20 mar. 2020.
} 
abordam as dificuldades em lidar com o amadurecimento pessoal, em especial quando esse processo se volta para o mundo da comunidade juvenil, que sofre com as vozes sociais de estabilização que a rodeiam.

Em janeiro de 2019, a empresa lançou, em sua plataforma digital, a série Sex Education, uma produção britânica criada por Laurie Nunn que retrata os problemas sexuais na adolescência de um modo divertido, sem que, com isso, perca-se a credibilidade do tema proposto. Dentre as diversas personagens e suas respectivas histórias, Eric Effiong se destaca pelo seu crescimento individual na trama. Adolescente negro, gay afeminado, filho de pais protestantes, o jovem passa por mudanças significativas ao longo dos episódios da série num processo de autoconhecimento do seu corpo, de sua sexualidade e, consequentemente, de sua identidade. Além do embate entre os ideais identitários que ele assume e as negativas do seu pai sobre as escolhas do filho, um trauma resultante do preconceito intrínseco à sociedade age sobre Eric de um modo muito brusco, traçando novos contornos para a sua identidade, que acabam por gerar polos contrários, em situações que se encontram posteriormente discutidas.

Diante disso, objetivamos, neste trabalho, situado no âmbito da Linguística Aplicada e ancorado nos postulados do Círculo de Bakhtin $^{6}$ (2011, 2015), analisar a construção identitária do personagem Eric Effiong a partir, tanto de sua visão sobre si mesmo, como da ótica daqueles que estão no seu entorno. Debruçamo-nos, ainda, sobre os dizeres de Butler (2003), de Louro (2000) e de Hall (2006) para cumprir com o objetivo proposto e discutir sobre a identidade e sobre o corpo. A partir de um estudo qualitativo de cunho interpretativista, utilizaremos como corpus de análise enunciados do personagem Eric e de outros integrantes da série que interagem com ele em momentos específicos.

Este artigo está esquematizado da seguinte maneira: primeiramente, apresentamos a concepção das forças centrípetas e centrífugas (BAKHTIN, 2015); em seguida, traçamos um panorama sobre a identidade e sobre o corpo (sexualidade e gênero social); na sequência, apresentamos a análise qualitativa dos dados da pesquisa; e, por fim, apresentamos as considerações finais.

\footnotetext{
${ }^{6}$ Trata-se de um grupo composto por estudiosos da linguagem, que trabalharam conjuntamente, no final dos anos 1920, na antiga União Soviética, principalmente, Mikhail Mikhailovitch Bakhtin, Valentin Nikoláievitch Volóchinov e Pável Medviédev, dentre outros.
} 
PERcursos Linguísticos • Vitória (ES) •v. 10 •n. 25 • 2020 • ISSN: 2236-2592 • Dossiê:

Discursos de resistência e corpos (re)existentes

\section{As forças centrípetas e centrífugas na teoria bakhtiniana}

O dialogismo é tido como a categoria unificadora da teoria bakhtiniana, visto que ele é classificado como um princípio interno à palavra. Nessa concepção, a linguagem é dialógica por natureza, pois ela está diretamente ligada à língua como interação, desenvolvida dentro do diálogo e rodeada por diversas vozes sociais. Esse diálogo, ao qual os autores do Círculo de Bakhtin se referem, não é tomado, aqui, no sentido estrito do termo, mas sim num sentido mais amplo, "não apenas como a comunicação em voz alta, de pessoas face a face, mas como qualquer comunicação discursiva, independentemente do tipo" (VOLÓCHINOV, 2017, p. 219), sendo capaz de revozear discussões ideológicas presentes na sociedade.

Ao adentrarmos nos estudos bakhtinianos, observamos que a concepção dialógica da linguagem recai "sobre o diálogo entre diferentes enunciados que se movimentam para formar novas vozes sociais e tornam o mundo da cultura dinâmico, na medida em que os enunciados, enquanto respondem ao já-dito, provocam diferentes respostas" (FARIA, 2007, p. 55). O discurso verbal, sob essa perspectiva, participa de um constante embate ideológico que responde, refuta, confirma, antecipa respostas e críticas, sempre dialogando com a imensa cadeia de enunciados do mundo (VOLÓCHINOV, 2017). Nesse sentido, as relações dialógicas podem ser compreendidas como "relações de sentido" entre enunciados que são proferidos por pessoas “sócio-ideologicamente organizadas" (FARIA, 2007, p. 55).

Os enunciados concretos, formados pela parte material (verbal ou visual) e pelo contexto de produção, de circulação e de recepção (SILVA, 2013, p. 49), axiologicamente valorativos e únicos, são produtos do diálogo ideológico e social. Conforme Bakhtin (2011, p. 288), "todo enunciado é um elo na cadeia de comunicação discursiva" e como tal, constróise a partir de outros enunciados. Essa cadeia discursiva se constitui a partir do movimento das forças de centralização e de descentralização que agem ininterruptamente sobre a língua.

Denominadas de forças centrípetas e de forças centrífugas, essas forças dispersantes agem sobre os enunciados de formas diferentes, cada uma com a sua especificidade. De acordo com Bakhtin (2015), as forças centrípetas são condicionadas pelo viés da "linguagem única", que diz respeito a "uma expressão teórica dos processos históricos da unificação e da centralização da linguística" (BAKHTIN, 2015, p. 39). As forças centrífugas, por sua vez, representam "processos de descentralização e separação" (BAKHTIN, 2015, p. 41, grifos do autor).

Cada enunciação concreta do sujeito do discurso é um ponto de aplicação tanto das forças centrípetas quanto das centrífugas. Nela se cruzam os processos de centralização e descentralização, unificação e separação, um basta não só a sua língua como materialização discursiva individual como também basta ao 
heterodiscurso, é seu participante ativo. E essa comunhão ativa de cada enunciado no heterodiscurso vivo determina a feição linguística e o estilo do enunciado em grau não inferior à sua pertença ao sistema normativo-centralizador da língua única (BAKHTIN, 2015, p. 42).

Assim, o que acontece no interior do enunciado é o "heterodiscurso dialogizado, anônimo e social como a língua" (BAKHTIN, 2015, p. 42), formado a partir do incessante movimento dessas forças que, ora tendem a uma língua única (forças centrípetas), ora tendem à estratificação do heterodiscurso social (forças centrífugas). Importante lembrar que as reflexões do Círculo de Bakhtin acerca da linguagem baseiam-se na teoria do romance e que, segundo o próprio Bakhtin (2015, p. 41), a "linguagem literária é apenas uma das linguagens do heterodiscurso e, por sua vez, também está estratificada em linguagens (de gêneros, tendências etc.)". Conforme o autor,

\begin{abstract}
enquanto as variedades básicas de gênero literário se desenvolvem no curso das forças centrípetas unificadoras e centralizadoras da vida verboideológica, o romance $e$ os gêneros da prosa literária que gravitam em torno dele formaram-se historicamente no curso das forças centrífugas descentralizadoras. Enquanto nas cúpulas socioideológicas a poesia resolvia uma tarefa de centralização cultural, nacional e política no mundo ideológico verbalizado, no mundo baixo, nas farsadas e tablados do teatro de feira ecoava um histriônico heterodiscurso, um arremedo de todas as "línguas" e dialetos, desenvolvia-se a literatura do fabliau e das canções de rua, provérbios, anedotas - onde não havia nenhum centro da língua, onde se levava a cabo o livre jogo como as "línguas" dos poetas, cientistas, padres, cavalheiros, etc., onde todas as "línguas" eram máscaras e não havia uma pessoa linguística autêntica e indiscutível (BAKHTIN, 2015, P. 42-43, grifos do autor).
\end{abstract}

Assim, também se constrói a linguagem das produções artísticas atuais, a partir do embate entre forças centrípetas e centrífugas, em contínuos movimentos centralizadores e descentralizadores. Cada enunciado constitui-se de uma unidade contraditória, a partir de duas tendências opostas. É nesse contexto que o nosso olhar se debruça sobre a série Sex Education. Interessa-nos investigar a construção identitária de Eric Effiong, personagem escolhido por pertencer à comunidade LGBTQIA+, comunidade esta que, como se sabe, é historicamente reprimida pelas vozes hegemônicas que interpelam os indivíduos e que permeiam as relações sociais.

\title{
A concepção de identidade e de corpo
}

Rodeada por fatores sociais e culturais que, por vezes, interferem no modo como os sujeitos se enxergam e se projetam no mundo, a construção identitária dos indivíduos acontece em meio à descontinuidade de suas ações, à contradição dos seus discursos e ao modo como eles são representados socialmente. Diante desse cenário, pensar num sujeito totalmente integrado, centrado e convicto de sua identidade una e contínua não condiz com os conflitos 
inerentes à vida humana, tendo em vista que esta muda de acordo com as situações. Ao discutir sobre identidade cultural, Hall (2006) traz à tona três concepções de sujeito que ajudam a compreender como a noção de identidade tem sido vista nos últimos séculos, a saber: sujeito do iluminismo, sujeito sociológico e sujeito pós-moderno.

A primeira diz respeito ao sujeito do iluminismo, o qual foi "baseado numa concepção da pessoa humana como um indivíduo totalmente centrado, unificado, dotado das capacidades de razão, de consciência e de ação" (HALL, 2006, p. 10). O sujeito do iluminismo permanecia o mesmo do início ao fim de sua existência. A segunda, por sua vez, refere-se ao sujeito sociológico, o qual era constituído na interação com a sociedade e cujo núcleo do "eu" era formado "num diálogo contínuo com os mundos culturais 'exteriores' e as identidades que esses mundos oferecem" (HALL, 2006, p. 11, grifo do autor). Já a terceira diz respeito ao sujeito pós-moderno, o qual não possui só uma, mas diversas identidades que são formadas e transformadas em relação ao modo como os indivíduos são representados ou interpelados pelos sistemas culturais que os rodeiam (HALL, 2006, p. 12).

A pós-modernidade influenciou o surgimento de um sujeito fragmentado, cujas antigas amarras que o delimitavam como totalmente integrado e centrado em si entraram em colapso (HALL, 2006, p. 9). Se antes se acreditava em um sujeito coerente do início ao fim de sua vida, agora esse mesmo sujeito passou a ser visto como provisório, com identidades múltiplas. Ainda de acordo com o autor, essa descentralização do "eu" constitui a chamada "crise de identidade" do sujeito pós-moderno que passou a ser visto como sendo um indivíduo com identidades contraditórias, continuamente deslocadas, formadas e transformadas ao longo do tempo.

Os estudos culturais contemporâneos contemplam essa fragmentação do sujeito em todas as suas nuances. Neles, observa-se que são estudadas "as identidades de classe, de gênero, de sexualidade, de etnia, de raça e de nacionalidade, além de suas características, de suas implicações e de suas prováveis consequências" (FARIA, 2007, p. 26). É nesse contexto que nos propomos a discutir identidade sexual, uma vez que ela, fazendo parte da vida do sujeito, também é "construída ao longo de toda a vida, de muitos modos, por todos os sujeitos" (LOURO, 2000, p. 5) e está diretamente ligada ao viés social.

Baseamos, assim, a discussão sobre identidade no fato de que, na contemporaneidade, as pessoas só se tornam inteligíveis quando os seus gêneros sociais entram em "conformidade com padrões reconhecíveis de inteligibilidade de gênero" (BUTLER, 2003, p. 37). Numa sociedade que reconhece, predominantemente, os corpos heterossexuais, por exemplo, a 
discussão acerca da influência do gênero e da sexualidade sobre a construção identitária dos indivíduos se torna imprescindível, uma vez que em torno desses corpos há vozes sociais conflitantes que determinam o modo como eles devem se portar no mundo.

Dessa forma, a partir dessa perspectiva, seria possível, concomitante à discussão de identidade, repensar o padrão de inteligibilidade estabelecido pela hegemonia, o qual, por meio de normas culturais de entidades estabilizadoras, aponta para uma concepção de "pessoa" cuja identidade é garantida por conceitos coerentes de um gênero estabilizador de sexo e de sexualidade (BUTLER, 2003). É, então, por esse motivo, que discutiremos identidade e corpo simultaneamente, pois um está diretamente ligado ao outro.

É importante frisar a relação de poder que existe sobre a construção identitária dos corpos descontínuos, pois a sociedade heteronormativa possui uma perspectiva de gênero ultrapassada que foi reproduzida no decorrer dos anos por meio dos discursos de regulação social dos corpos. Para eles, o heterossexual é a referência, o que deve ser seguido, uma vez que condiz com o sexo biológico; e o homossexual é o transgressor, o que deve ser taxado negativamente. Louro (2000, p. 9, grifos do autor) explica essa visão hegemônica da seguinte maneira:

Em nossa sociedade, a norma que se estabelece, historicamente, remete ao homem branco, heterossexual, de classe média urbana e cristão e essa passa a ser a referência que não precisa mais ser nomeada. Serão os "outros" sujeitos sociais que se tornarão "marcados", que se definirão denominados a partir dessa referência. Desta forma, a mulher é representada como "o segundo sexo" e gays e lésbicas são descritos como desviantes da norma heterossexual.

Sendo eles "desviantes" do projeto social, os corpos homossexuais são os que mais sofrem no processo de auto identificação devido ao poder dos discursos dominantes de centralização. A heteronormatividade estabelece o que é aceitável socialmente, cabendo aos indivíduos se adequarem às diretrizes para que eles possam ser aceitos. Normalmente, a construção identitária dessa comunidade é seguida pelo silêncio, pois "a produção da heterossexualidade é acompanhada pela rejeição da homossexualidade. Uma rejeição que se expressa, muitas vezes, por declarada homofobia" (LOURO, 2000, p. 18). Isso acontece numa tentativa criminosa de contenção dos corpos transgressores que, muitas vezes, por medo ou por vergonha, acabam fechados em si.

Os conflitos identitários começam na negação do "eu" e na busca por características que apontem para o centro. Hall (2006) explica que "dentro de nós há identidades contraditórias, empurrando em diferentes direções, de tal modo que nossas identificações estão sendo continuamente deslocadas", o que é uma característica do sujeito pós-moderno que permite que assumamos identidades diferentes a depender da ocasião. Além disso, assim 
como a identidade, "o corpo é uma situação" (BUTLER, 2003, p. 27), interpretado e interpelado por fatores sociais que atuam sobre ele de um modo injuntivo, o que influencia as mudanças.

O sujeito possui identidades contraditórias, porque ele, assim como as vozes que o rodeiam, é contraditório. Ele transita entre o que é o certo para ele e o que o mundo acredita

ser certo. É, pois, nesse meio, que as diferentes identidades dos sujeitos se fragmentam e se constroem, sejam identidades realmente aceitas pela sociedade, sejam identidades que contenham verdades camufladas. Em meio ao labirinto de possibilidades no qual ele se encontra, o sujeito busca por algo que o faça se sentir completo, mesmo que, para isso, ele abandone e adote novas identidades no percurso.

Eric Effiong, da série Sex Education, pode ser visto como a representação do sujeito pós-moderno que sofre com a transitoriedade de sua identidade. Os discursos que o rodeiam e as interpelações sociais fazem com que ele não fique preso num "eu" coerente. O modo como o social age sobre esse personagem torna-se mais marcado devido ao fato de ele ser, além de um corpo transgressor, negro, aspecto que o faz ser duplamente oprimido e significativamente modificado socialmente.

\section{A atuação das forças centrípetas e centrifugas em enunciações concretas}

A trajetória de Eric Effiong na série Sex Education apresenta peculiaridades que o permitem ser muito mais do que apenas o amigo gay e engraçado do menino heterossexual em mais uma representação artística da Netflix. Apesar de Eric não desempenhar o papel do personagem principal, a sua história e os problemas enfrentados por ele no processo de sua construção identitária fazem com que milhares de pessoas observem a aproximação entre o roteiro e a vida real. Conforme visto anteriormente, a identidade é processual, provisória e se constrói nas relações sociais, nas práticas discursivas que estabelecemos uns com os outros, em momentos historicamente definidos. No caso específico de Eric, essa construção se dá, principalmente, a partir das pressões familiares acerca do seu modo de ser, da aceitação dos seus pares no colégio e do caso de agressão por homofobia. Sendo assim, analisaremos, a seguir, alguns enunciados concretos retirados de cenas específicas dos episódios da primeira temporada da série de modo a entender como se dá a construção identitária desse personagem.

Eric Effiong se destaca dentre os demais personagens por sua personalidade forte, por suas roupas com cores divertidas e por sua energia. O jovem esbanja carisma e, até determinado momento, autoconfiança, posto que ele é assumidamente gay e não possui 
nenhum problema em discutir abertamente sobre as suas aventuras sexuais no seu círculo de amizade. No decorrer dos episódios da primeira temporada da série, podemos acompanhar, no entanto, essa perda da autoconfiança, o que faz o jovem passar por um momento de transição durante o qual ele se permite adotar outros comportamentos, na busca pelo autoconhecimento. Vejamos a imagem que melhor representa a essência desse personagem na série como um todo (Figura 1).

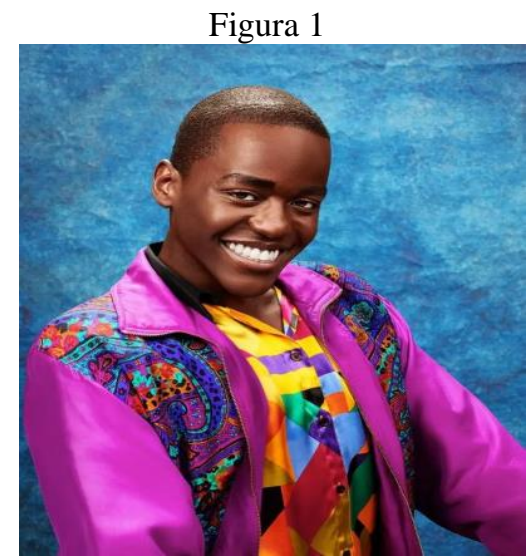

Fonte: https://www.buzzfeed.com/adeonibada/ncuti-gatwa-eric-sex-education-wash-hands-netflix acesso em 27 mar. 2020.

Apesar de a imagem passar a ideia de um indivíduo confiante e convicto de si, essa expectativa é quebrada ao longo dos episódios, conforme mencionado acima. Além disso, sendo Eric um dos representantes da comunidade LGBTQIA+ na série, todas as enunciações que o rodeiam são permeadas por forças sociais que atuam incessantemente e que ajudam a perpetuar, muitas das vezes, a intolerância de uma sociedade conservadora sobre os corpos ditos transgressores na tentativa de estabilizar as instituições de poder, o que também influencia a fragmentação do personagem. É, pois, em tal cenário que Eric se vê interpelado a experimentar comportamentos contraditórios enquanto busca se enquadrar em um campo específico da sociedade.

Nas primeiras enunciações do personagem, tudo indica que temos diante de nós um indivíduo plano e contínuo, com especificidades constantemente reiteradas que são facilmente reconhecíveis na construção de sua história: muitos risos, piadas clichês etc. Antes de conhecermos o núcleo familiar de Eric, parece-nos que o personagem não passa por conflitos internos, o que nos faz caracterizá-lo, inicialmente, como sendo o protagonista de uma história já vista antes em séries de TV: o menino gay afeminado que se veste com roupas diferentes e é engraçado por natureza. Porém, quando tomamos conhecimento do entorno doméstico no 
qual ele está inserido, compreendemos que algumas mudanças acontecem e que os conflitos são inevitáveis dadas as circunstâncias das tensões que se aplicam.

A evolução do personagem em questão acontece tanto na dimensão social quanto na dimensão pessoal. Todas as enunciações, propícias à aplicação das forças (des)centralizantes, influenciam no embate identitário na construção de Eric, conforme veremos adiante. Comecemos, então, pela CENA 1 .

Esta cena diz respeito a um diálogo entre Eric e Lily, uma personagem secundária da série. Vejamos:

\section{CENA 1}

Lily - Você se veste de mulher?

Eric - Não! Quero dizer, gosto de me vestir, mas não sou trans.

Lily - Vamos nos $\operatorname{montar}^{7}$ ?

Eric - Sério? Tudo bem.

No Episódio 3, Lily abre o guarda-roupa de Eric e nota a presença de algumas peças femininas. Em um processo de curiosidade, a menina o questiona sobre as roupas com o intuito de saber se elas pertencem às irmãs do jovem ou se ele as utiliza para se montar. Apesar de não ser uma pergunta com tom de julgamento, o instinto de Eric o faz negar: “não!”. Essa resposta espontânea pode ter sido influenciada pela compreensão de que o discurso hegemônico heteronormativo condena tal conduta e, sendo assim, a menina iria julgá-lo. Como se sabe, o aceitável pela sociedade é que homens se vistam como homens e mulheres como mulheres; que meninos vistam azul e meninas vistam rosa. A negativa espontânea é influenciada por uma força centralizadora que leva o discurso do jovem ao encontro daquilo que é disseminado socialmente como correto, isto é, a força centrípeta agindo sobre a linguagem. No entanto, no segundo seguinte, quando ele afirma que, na verdade, gosta de usar aquelas vestimentas, a expectativa inicial é quebrada, entrando em cena a força centrífuga, que desestabiliza o que foi dito anteriormente. Nesse momento, o discurso vai de encontro ao da estabilidade e inicia-se um embate de posicionamentos. Percebemos, ainda, que há um

\footnotetext{
7 O termo "montar", aqui utilizado, refere-se ao processo de produção de uma personagem, o qual envolve diversos fatores como, por exemplo, a preparação da pele, a aplicação da peruca, a escolha das vestimentas, dentre outros procedimentos.
} 
certo conflito interno que transita entre o que é certo para ele e o que é certo para a sociedade e que isso pode mudar a sua perspectiva de mundo.

A recusa inicial do jovem quanto ao questionamento pode ser relacionada ao cenário machista que continua sendo propagado pelo discurso de sexo biológico como estabilizador de gênero, o qual determina que homens e mulheres devem seguir aquilo que lhes foi préestabelecido desde o nascimento. Entretanto, a discussão vai muito além do rótulo acerca do sexo biológico, posto que essa transformação visual, na qual um homem se veste de mulher, é, para muitos, o seu trabalho, ou melhor especificando, uma representação artística que não se relaciona ao gênero. Jesus (2012, p. 14) deixa isso claro ao explicar que o "gênero com o qual uma pessoa se identifica [...] pode ou não concordar com o gênero que lhe foi atribuído quando de seu nascimento. Diferente da sexualidade da pessoa. Identidade de gênero e orientação sexual são dimensões diferentes e que não se confundem”. Isso significa que a orientação sexual dos indivíduos é definida pela atração, está diretamente ligada à sexualidade do sujeito, e não pelo modo como se vestem, já que isso pode variar de acordo com a cultura ou com a simples escolha de cada um.

De volta à análise, e ainda no Episódio 3, o cenário de redenção é desestabilizado quando o pai de Eric entra no quarto e vê o filho e a colega montados, isto é, vestidos com as peças femininas do guarda-roupa do jovem, e maquiados, assistindo a um filme adulto para homossexuais. Após um momento de tensão, Lily é solicitada a ir para casa e mais um diálogo importante acontece. Vejamos o diálogo na CENA 2:

\section{CENA 2}

Eric - Pai, não era... só estávamos nos divertindo... vestindo...

Pai de Eric - É hora de você amadurecer. Trabalhar, ter responsabilidades. Ver como é o mundo real. Tire essa coisa do seu rosto antes que a sua mãe veja.

Apesar de ser algo de extrema importância, a sexualidade ainda é pouco discutida, principalmente no meio familiar - a falta de informação pode gerar a ignorância sobre alguns fatores como o gênero e a orientação sexual. $\mathrm{O}$ assunto gera controvérsias, mas o que nos importa, aqui, são aqueles que tentam camuflar os sentimentos com receio do que terceiros possam pensar. É comum que os adolescentes escondam as suas orientações sexuais dos seus pais numa tentativa de autoproteção ou por medo de serem rejeitados, o que é totalmente compreensível, tendo em vista o preconceito social em torno dos corpos transgressores. Vale 
salientar que a família de Eric é bastante religiosa, que ele é filho de pais protestantes, e que aquela performance poderia gerar um embate maior com o sagrado, com o bíblico, podendo, ainda, ser condenada pela igreja. Diante disso, Eric, nesta cena, tenta amenizar a surpresa do pai ao presenciar aquela situação negando o que ele sente. Ao perceber a tensão que foi criada, ele não só tenta se proteger como também busca proteger o pai ao insinuar que ele e Lily estavam somente se divertindo: "Pai, não era... só estávamos nos divertindo... vestindo...". Nesse enunciado, é possível perceber um embate entre as vozes dominantes que condenariam aquela atitude e a voz do próprio Eric, ao tentar provar para o pai que não há nada de mais em se divertir com uma amiga.

Mesmo com a tentativa de contornar a situação, não são todos os sujeitos que acompanham as mudanças de ordem estrutural que vêm acontecendo no mundo, há anos, a partir das lutas das minorias. Percebemos isso no enunciado do pai de Eric quando aquele diz que está na hora de o seu filho crescer, ter responsabilidades. A enunciação do homem vem carregada axiologicamente com estigmas comuns à comunidade LGBTQIA+ atribuídos por pessoas que tentam a todo custo manter um pensamento ultrapassado. É comum que aqueles que fazem escolhas destoantes da grande massa sejam chamados de vagabundos. $\mathrm{O}$ amadurecimento, ao qual o pai de Eric se refere, está ligado à perspectiva ideológica disseminada pela sociedade de que o homem deve trabalhar para manter a casa, fazendo-o, subjetivamente, caminhar em direção a essas vozes sociais conflituosas. Mesmo se, naquele momento, o homem não acreditasse naquilo que estava sendo proferido, aquele era o discurso necessário para obtenção da estabilidade. Contudo, o discurso é, ao mesmo tempo, estratificante, na medida em que ele, implicitamente, está chamando o seu filho de vagabundo.

O uso de peças femininas e o preconceito social em torno desse ato também envolve o próximo conflito, agora no Episódio 5. Desta vez, Eric e o seu amigo Otis combinam de assistir ao Hedwig: rock, amor e traição ${ }^{8}$. Essa é uma tradição dos amigos. Todos os anos, no dia do aniversário de Eric, eles se vestem a caráter - com roupas femininas, maquiagem e peruca - e vão assistir ao show. No entanto, algo mais sério estava prestes a acontecer, pois Eric acaba ficando sozinho e, tendo sido furtado, fica também sem dinheiro para o ônibus,

\footnotetext{
${ }^{8}$ Filme musical lançado em dezembro de 2001 que retrata a história de Hansel, jovem que sonha em se tornar uma estrela do rock. Contudo, para que esse e outros sonhos possam se tornar realidade, Hansel se submete a uma cirurgia de mudança de sexo, a qual dá origem a Hedwig, uma cantora com figurino e maquiagem extravagantes. Disponível em: https://www.papodecinema.com.br/filmes/hedwig-rock-amor-e-traicao/. Acesso em: 21 mai. 2020.
} 
sendo ele obrigado a ir sozinho para casa numa estrada deserta. A CENA 3 pode ser considerada um dos momentos determinantes para a evolução pessoal do garoto na série, pois configura um grande trauma na vida do jovem.

\section{CENA 3}

Homem - Aonde você vai? Com licença, senhorita. Quer carona?

Eric- Não, obrigado.

Homem - Tem pênis, senhorita? Vai, mostra o seu pau.

Eric - Me deixa em paz, por favor.

* Eles jogam o carro na frente do jovem *

Homem - Gay nojento (ainda dentro do carro).

* Os homens descem do carro *

Eric - Por favor, não sou assim. É uma fantasia. Ia ver um filme com um amigo. Não sou...

* Eric é agredido. O homem cospe no garoto enquanto este está caído no chão *

Primeiramente, reflitamos sobre as dificuldades do corpo LGBTQIA+ em ser aceito socialmente. A homofobia, além de representar uma violência contra os corpos estigmatizados pelos sistemas de controle social, assim como as escolhas desse grupo, as vestimentas, o amor etc., representa um retrocesso nas lutas a favor da democracia e do respeito pelo cidadão, independentemente da cor, da raça ou da orientação sexual deste. É uma atitude que rebaixa os indivíduos como se os direitos dos oprimidos fossem menores do que os daqueles que vivem para propagar os dizeres da normatividade. Ela é expressa, acima de tudo, "pelo desprezo, pelo afastamento, pela imposição do ridículo" (LOURO, p. 19) ou, melhor dizendo, ela designa

\footnotetext{
dois aspectos diferentes da mesma realidade: a dimensão pessoal, de natureza afetiva, que se manifesta pela rejeição dos homossexuais; e a dimensão cultural, de natureza cognitiva, em que o objeto da rejeição não é o homossexual enquanto indivíduo, mas a homossexualidade como fenômeno psicológico e social. Essa distinção permite compreender melhor uma situação bastante disseminada nas sociedades modernas que consiste em tolerar e, até mesmo, em simpatizar com os membros do grupo estigmatizado, no entanto, considera inaceitável qualquer política de igualdade a seu respeito (BORRILLO, 2010, p. 22, grifo nosso).
}

Essa tolerância e simpatia pelos homossexuais servem como camuflagem para o real sentimento de muitas pessoas que não aceitam a diferença. As leis criadas para manter a integridade do corpo homossexual não são, muitas das vezes, o suficiente para conter a 
permanente disseminação da intolerância. Na CENA 3, o enunciado "gay nojento" deixa claro o dilema da homofobia e concentra várias vozes em uma só. Essa enunciação, no embate das forças centrípetas e centrífugas, enquanto eleva o preconceito de um grupo (concatenando o pensamento hegemônico da heteronormatividade), fere a luta LGBTQIA+, fragilizando o grupo. Além disso, quando Eric nega a sua essência - "não sou assim" - perante o seu agressor para se proteger, ele nos mostra a dificuldade de se assumir socialmente, ao ponto de ser necessária a negação da sua própria identidade para não ter o seu corpo violado. As forças centrípetas agem sobre o enunciado do jovem que tenta aproximar o seu corpo do que é tido como normal para que possa haver piedade por parte do agressor; já as forças centrífugas agem sobre o mesmo enunciado na medida em que desestruturam a concepção de si que Eric tinha, pois o fazem autonegar-se: negar a sua comunidade, a sua luta e os seus direitos como cidadão.

O desdém e a agressividade em relação aos que não seguem o modelo de referência estabelecido pela sociedade causam danos psicológicos que podem mudar completamente o sujeito vítima de tal agressão, como é o caso de Eric. Diante da negativa do pai, dos conflitos em ser ou não ser e da homofobia, a auto identificação do jovem entra em declínio. A duplicidade faz o jovem pensar que a sua identidade, naquele momento, estava-o fazendo sofrer. Como resposta ao meio, Eric passa a adotar os discursos e o sentimento de ódio ao seu redor numa tentativa de centralizar o seu "eu" e de ir ao encontro da hegemonia.

A mudança de Eric começa pelo visual. Se antes ele se vestia com roupas extravagantes, que faziam jus à identidade então adotada, agora ele se restringe a roupas em tons neutros, o que está diretamente ligado ao apagamento de si, numa clara identificação de que ele perdeu as cores em todos os sentidos. Agora, ele passa a ser neutro tanto no visual, quanto na alegria, como se ele quisesse se misturar à multidão, conforme podemos ver na imagem abaixo (Figura 2).

Figura 2

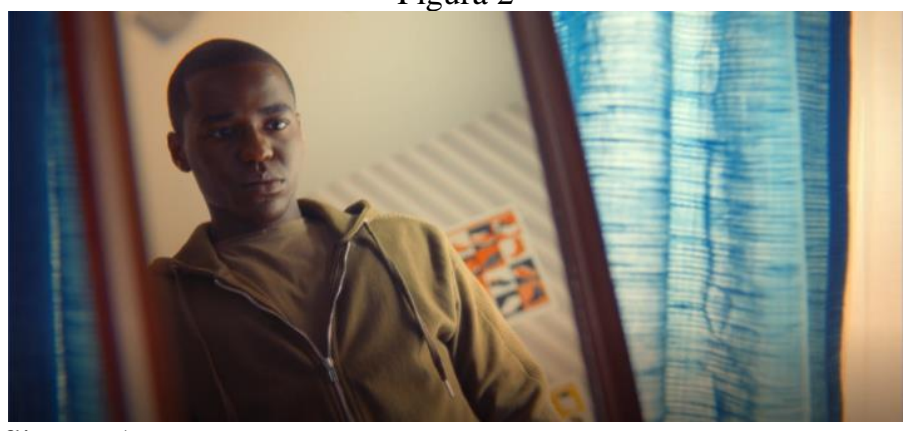

Fonte: https://www.netflix.com/ 
Como é de se esperar, a agressão muda completamente o modo de Eric se portar no mundo. Ao que tudo indica, o fato de ele ter sido agredido quando estava montado, performando uma imagem condenada pelos radicais heteronormativos, faz com que ele enxergue a sua essência como perigosa para a sua integridade, fazendo-o se sentir responsável por essa ação. Não obstante, esse tipo de pensamento culposo que se alastra em Eric é o mesmo que muitos da comunidade LGBTQIA+ passam a ter após um episódio de homofobia. Vale salientar que, apesar de serem vítimas, os participantes de tal comunidade não estão imunes a esse sentimento de ódio, tendo em vista que o ambiente no qual eles crescem, normalmente com interiorização da violência, insultos e condenações morais, propicia o repasse do sentimento de repressão para os seus pares (BORRILLO, 2010). Esse cenário, portanto, "impele um grande número de homossexuais a lutarem contra os seus desejos, provocando, às vezes, graves distúrbios psicológicos, tais como sentimento de culpa, ansiedade, vergonha e depressão" (BORRILLO, 2010, p. 101). Essa acentuação axiológica de repressão é, possivelmente, o que leva Eric, no Episódio 6, a agredir Anwar, um colega também gay, logo após ter sido vítima de homofobia. Depois disso, ele tenta conversar com Anwar e se inicia um diálogo importante entre os dois (CENA 4).

\section{CENA 4}

Eric - Ei, cara, podemos conversar?

Anwar - Vai me bater?

Eric - Não.

Anwar - Vou adivinhar. Lugar e hora errados, certo?

Eric - Achei que ia me sentir bem, mas não senti.

Anwar - Bater no outro gay. Perfeito, Eric.

Eric - Eu sinto muito.

Anwar - Se ajuda, eu aproveitei isso para me assumir para a minha mãe.

Eric - Ela não sabia? Achei que você era assumido.

Anwar - Bem, achou errado. E agora ela acha que você é homofóbico. Então, se uma senhora indiana te olhar feio, não é nada pessoal. 
Essa cena demonstra a perspectiva de Borrillo (2010) sobre a repressão por tabela das pessoas vítimas de homofobia. Sendo os homossexuais historicamente reprimidos, eles acabam assumindo uma posição de ditadores e acabam prejudicando os seus pares num processo infinito de julgamento e de intolerância que, na verdade, deveria ser combatido por eles. Diante do ato de agressão, Eric diz ao colega que achava que iria se sentir bem, mas que não se sentiu. Nesse enunciado, as forças centrípetas e centrífugas se fazem presentes: as primeiras, no sentido em que elas unificam o pensamento de que a agressão cura tudo, inclusive a diferença do outro; as segundas, no sentido em que Eric se vê como perpetuador da intolerância que antes o havia feito sofrer. É claro que ele acreditava que ao repassar o choque recebido iria se sentir parte do centro estabilizador. Porém, ele rapidamente passa de vítima de homofobia para reprodutor de homofobia: "e agora ela acha que você é homofóbico".

Depois desse processo, numa cena subsequente, Eric tem contato com a representação de uma imagem que está mais próxima do seu "eu" interior do que a nova personalidade conflituosa que ele havia assumido. Ele se enxerga na imagem de um homem, aparentemente bem-sucedido, que usa roupas extravagantes, grandes brincos e unhas pintadas sem receio, fazendo-o se auto perceber como indivíduo. Esse reconhecimento de si no outro está ligado ao que Hall (2006, p. 38-39, grifo do autor) elucida quando o autor diz que "em vez de falar da identidade como uma coisa acabada, deveríamos falar de identificação, e vê-la como um processo em andamento". É exatamente essa identificação que faz Eric enxergar, no Episódio 7, que não havia nada de errado em ser quem ele era antes de todos os conflitos acontecerem. A partir desse contato normatizador, quanto às escolhas do jovem e, ao mesmo tempo, desestabilizador, no sentido de que o fez abandonar o discurso hegemônico, Eric nos apresenta um novo eu, com a identidade renovada e modificada, assumindo de vez a sua sexualidade perante a família e amigos (CENA 5).

\section{CENA 5}

Eric - Suas unhas são poderosas.

Homem - Obrigado, garoto. Quer um conselho? Aposte nos tons de pedras preciosas.

O enunciado "aposte nos tons de pedras preciosas" é tão importante para última mudança de Eric na primeira temporada da série que a cor do glitter que o jovem usa nos olhos na noite do baile do colégio remete à esmeralda. Conforme se verifica, esse enunciado é 
PERcursos Linguísticos • Vitória (ES) •v. 10 •n. 25 • 2020 • ISSN: 2236-2592 • Dossiê:

Discursos de resistência e corpos (re)existentes

atravessado tanto pelas forças centrípetas quanto pelas forças centrífugas, no sentido de que as pedras preciosas, de alto valor material, são metaforizadas numa relação entre o jovem e o homem com quem fala (Figura 3).

Figura 3

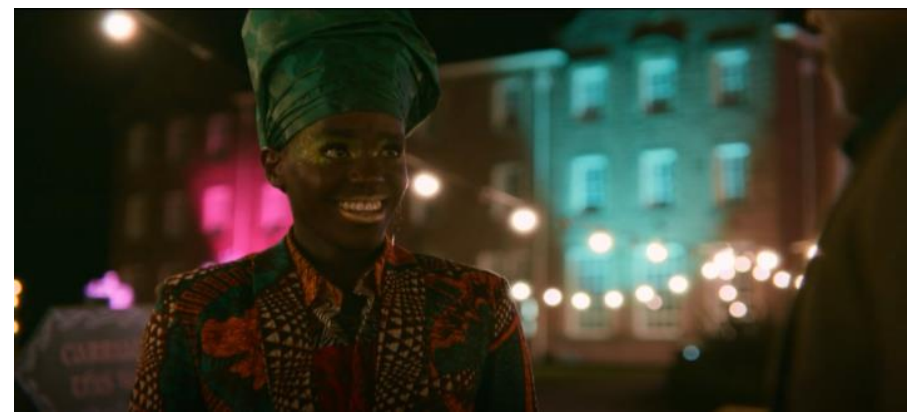

Fonte: https://www.netflix.com/

Diante do exposto, compreendemos que a construção identitária de Eric se dá a partir de enunciados (seus e daqueles ao seu redor), atravessados pelo movimento ininterrupto das forças centrífugas e centrípetas.

\section{Considerações finais}

Ao longo deste trabalho, podemos perceber que os problemas enfrentados por Eric Effiong no seu processo de auto identificação são fundamentais para o crescimento pessoal do personagem em Sex Education. As análises revelam as forças sociais conflitantes de centralização e de descentralização - forças centrípetas e forças centrífugas - que incessantemente atravessam as enunciações concretas da série e que interferem na construção identitária do personagem, deslocando-o do e para o centro. Além disso, apontam para mudanças significativas nessa construção identitária, corroborando com a concepção de sujeito pós-moderno (HALL, 2006), para quem as identidades são formadas e transformadas pelo tempo e pelo modo como este é interpelado pelos sistemas sociais. 
PERcursos Linguísticos • Vitória (ES) •v. 10 •n. 25 • 2020 • ISSN: 2236-2592 • Dossiê:

Discursos de resistência e corpos (re)existentes

Por ser um representante da comunidade LGBTQIA+, Eric é continuamente rodeado por discursos axiologicamente valorados por estigmas que também interferem no modo como o jovem se vê no mundo. O trauma causado pela homofobia, como podemos ver, é desconcertante na medida em que o personagem assume um caráter de neutralidade, além de passar a se ver como perigoso para a sua própria integridade física. No entanto, o processo de identificação com o outro o faz mirar o seu próprio interior e reencontrar o seu verdadeiro eu. Nesse sentido, portanto, podemos dizer que a homofobia é o fio condutor na construção identitária do personagem, levando-o da euforia ao reencontro consigo mesmo, passando pela sensação traumática da violência e da negação.

\section{Referências}

BAKHTIN, M. Estética da criação verbal. 6. ed. São Paulo: Editora WMF Martins Fontes, 2011.

BAKHTIN, M. Teoria do romance I: A Estilística. Tradução de Paulo Bezerra. São Paulo: Editora 34, 2015.

BORRILLO, D. Homofobia: história e crítica de um preconceito. Belo Horizonte: Autêntica Editora, 2010.

BUTLER, J. Problemas de gênero: feminismo e subversão da identidade. Rio de Janeiro: Civilização Brasileira, 2003.

FARIA, M. V. B. A construção estilística das identidades poéticas da cidade de Natal: um olhar bakhtiniano. 2007. 188f. Tese (Doutorado em Letras) - Universidade Federal do Rio Grande do Norte, Natal, RN, 2007.

HALL, S. A identidade cultural na pós-modernidade. 11. ed. Rio de Janeiro: DP\&A, 2006.

JESUS, J. G. Orientações sobre identidade de gênero: conceitos e termos. Brasília: Autor (publicação online), $2012 . \quad$ Disponível em: https://files.cercomp.ufg.br/weby/up/16/o/ORIENTA\%C3\%87\%C3\%95ES_POPULA\%C3 \%87\%C3\%83O_TRANS.pdf?1334065989. Acesso em: 29 mar. 2020.

LOURO, G. L. O corpo educado: pedagogias da sexualidade. 2.ed. Belo Horizonte: Autêntica, 2000. 
PERcursos Linguísticos • Vitória (ES) •v. 10 •n. 25 • 2020 • ISSN: 2236-2592 • Dossiê:

Discursos de resistência e corpos (re)existentes

SILVA, A. P. P. Estudos do discurso: perspectivas teóricas. São Paulo: Parábola, 2013. p. 4569.

VOLÓCHINOV, V. Marxismo e filosofia da linguagem: problemas fundamentais do método sociológico na ciência da linguagem. 1.ed. São Paulo: Editora 34, 2017. 